\title{
Strong-Arm Bullying Prior to Incarceration Among a Sample of Young Offenders
}

\author{
Kimberly Bender \\ University of Denver \\ Brian Perron \\ University of Michigan
}

\author{
Matthew O. Howard \\ University of North Carolina at Chapel Hill \\ Jeffrey M. Jenson \\ University of Denver
}

\begin{abstract}
Most studies of bullying behavior have been conducted with general populations during childhood and early adolescence. Although incarcerated youth are at increased risk for bullying others, incarcerated youth in the United States have rarely been studied regarding their bullying behavior prior to incarceration. Understanding the psychological and antisocial correlates of strong-arm bullying prior to incarceration may highlight risk factors that, if addressed, might reduce bullying and deter youth from further involvement in the juvenile justice system. This study examines selfreports of 723 youth incarcerated in the Missouri Division of Youth Services to determine the demographic, psychiatric, and substance-related factors associated with strong-arm bullying in the year prior to incarceration. Results indicate that younger youth from urban areas who have extensive histories of delinquent behavior are more likely than other incarcerated youth to strongarm their peers. Youth exhibiting strong-arm bullying were also more likely than other youth to use cigarettes and alcohol. Further, strong-arm bullying is associated with severe offending, including gang membership and physical violence. These psychosocial correlates suggest behavioral targets for intervening to reduce bullying among delinquent youth.
\end{abstract}

\section{Keywords: bullying, delinquency, incarcerated youth, mental health, substance use}

Bullying, defined as aggressive behavior used to repeatedly harm or intimidate others with less power (Olweus, Limber, \& Mihalic, 1999), is a significant social problem among children and adolescents (Glew, Fan, Katon, \& Rivara, 2008). Bullying inherently involves an imbalance of power, and is most frequently manifested in physical or psychological aggression, with bullies intimidating their victims through threats, name calling, social exclusion, gossip (in person or via the Internet), and physically aggressive acts such as punching or slapping (Nansel et al., 2001). Approximately 1 in 4 U.S. youth report bullying others or being a victim of bullying (Glew et al., 2008). Bullying has serious emotional consequences for the victims, including anxiety (Sourander et al., 2007), depression, low self-esteem (Olweus, 1994), and academic problems (Eisenberg, Neumark-Sztainer, \& Story, 2003).

Although characteristics associated with bullying have been examined in community samples, little is known about the correlates of incarcerated youths' bullying behaviors prior to their incarceration.

This study was supported by grants DA021405 (Natural History, Comorbid Mental Disorders, and Consequences of Inhalant Abuse, M.O. Howard, PI), and DA15929

(Neuropsychiatric Impairment in Adolescent Inhalant Abusers, M.O. Howard, PI) from the National Institute on Drug Abuse, National Institutes of Health, USA.

Correspondence concerning this article should be addressed to Kimberly Bender, kimberly.bender@du.edu. Author Note continued on page 11.
Understanding factors associated with bullying behavior may suggest concurrent risk factors that, if addressed, might serve to prevent or reduce bullying among this high-risk population. Therefore, this study focused on understanding factors associated with youths' strong-arm bullying of other students prior to incarceration.

\section{Background Literature}

Although few studies have examined bullying correlates among samples of U.S. incarcerated youth, several studies using general population samples have identified individual, peer, and family factors that are associated with bullying others. For example, mental health problems are more common among bullies than nonbullies; consequently, bullies are more likely than other youth to be referred for mental health services (Kumpulainen, Rasanen, \& Puura, 2001). Studies have suggested that high rates of conduct disorder, oppositional defiant disorder, attention deficit disorder, and depression are common among youth who bully others (Kumpulainen et al., 2001; Kumpulainen, Rasanen, \& Henttonen, 1999; Sourander et al., 2007). Passive aggressive, histrionic, paranoid, and dependent personality traits have been noted frequently in bullies (Coolidge, DenBoer, \& Segal, 2004). Investigators have also found that bullying was associated with neuropsychological dysfunction and executive function deficits (Coolidge et al., 2004). Bully/Victims, which are youth who report both bullying others and being victimized by bullies, demonstrate the worst 
psychosocial functioning as compared to either bullies or victims.

Several studies point to the fact that childhood bullies are often quite persuasive and powerful among their peers (Berthold \& Hoover, 2000). Childhood bullies often report greater ease in making friends than victims who often experience high levels of isolation and loneliness (Nansel et al., 2001). Bullies also belong to diverse friendship groups including both popular and unpopular peer groups as well as groups that display aggressive and nonaggressive behaviors (Estell, Farmer, \& Cairns, 2007).

In regard to family correlates, research has suggested that youth with low levels of familial affection and minimal monitoring by parental figures are also at elevated risk for bullying others (Olweus, 1999). Further, bullies are more likely than nonbullies to come from families that use inconsistent, authoritarian parenting styles and harsh discipline (Connolly \& O'Moore, 2003).

Youth who bully their peers are more likely than nonbullies to engage in other high-risk behaviors such as alcohol and other drug use, which have been found to be common among bullies (Berthold \& Hoover, 2000; Nansel et al., 2001). In addition, bullies have reported higher rates of poor academic achievement, negative attitudes toward school, and early participation in sexual behavior than nonbullies (Berthold \& Hoover, 2000; Nansel et al., 2001). More important, these and other antisocial behaviors often persist or increase during late adolescence and adulthood. Thus, as young bullies age into older adolescence and young adulthood, they are at increased risk for gang involvement (Viljoen, O'Neill, \& Sidhu, 2005) and criminal behavior (Sourander et al., 2007). Moreover, individuals who bully others at a young age experience high conviction rates, substance abuse, and frequent depression and anxiety disorders during adulthood (Sourander et al., 2007).

Although bullying behavior is pervasive among young offenders (e.g., Ireland \& Monaghan, 2006), few studies have examined the individual, peer, and familial factors associated with bullying behavior among incarcerated youth. Bullying studies of incarcerated youth have been conducted almost entirely outside the United States (Ireland, 2000), and have focused primarily on bullying within detention settings rather than investigating the risk factors associated with bullying behaviors that preceded incarceration. As such, little is known about which risk factors should be targeted to reduce or prevent bullying behavior among high-risk youth in the United States.

Researchers in the United Kingdom (Ireland, 1999; Ireland \& Power, 2004) and Canada (Connell \& Farrington, 1996; Viljoen et al., 2005) have investigated bullying among youth who were later incarcerated. These studies have found that bullying among offender populations is associated with being younger (i.e., adolescent verses adult; Connell \& Farrington, 1996) and have suggested that physical aggression, verbal aggression, anger, hostility (Ireland \& Archer, 2004), low empathy (Ireland, 1999), suicide attempts (Viljoen et al., 2005), and loneliness (Ireland \& Power, 2004) are related to bullying among incarcerated youth. Further, these investigators found that bullying was associated with youths' extensive criminal involvement, frequent incarceration, formation of social networks with other inmates (Connell \& Farrington, 1996), spending more time in prison (Power, Dyson, \& Wozniak, 1997), and displaying negative behavior toward justice staff (Ireland \& Monaghan, 2006). Other studies abroad indicate that incarcerated bullies were more likely than other youth to buy, sell, and abuse drugs (Ireland \& Monaghan, 2006; Viljoen et al., 2005). Although extensive research on bullying among incarcerated youth has taken place internationally, much of this research examined bullying within the detention or incarceration settings rather than elucidating the factors important for intervening with bullies prior to their incarceration.

The current study aimed to address these gaps in the literature by studying correlates of strong-arm bullying among youth incarcerated in the United States by specifically examining physically coercive behavior in the year prior to incarceration. This study was informed by ecological systems theory (Bronfenbrenner, 1994) that posits a child's development is contingent upon multiple complex subsystems and interactions among such subsystems. Thus, information gained from understanding the individual, social, and community factors associated with bullying prior to incarceration among U.S. youth may help practitioners and policy makers identify children who are most likely to bully their peers during childhood and early adolescence. Such understanding may also suggest malleable risk factors within different ecological subsystems for targeted interventions to help prevent or reduce bullying and other antisocial behaviors among a high-risk group of youth. The current study identifies psychosocial factors associated with strong-arm bullying prior to incarceration among youth in a state juvenile justice system located in the Midwestern United States. The investigation uses a sample of incarcerated youth to examine three research questions:

1. What is the prevalence of strong-arm bullying prior to incarceration among a representative sample of incarcerated youth?

2. What demographic, psychiatric, and substance-related factors are associated with strong-arm bullying prior to incarceration 


\section{PSYCHOLOGICAL CORRELATES OF BULLYING}

among youth incarcerated in the United States?

3. What antisocial behaviors are associated with strong-arm bullying prior to incarceration among young offenders?

\section{Method}

\section{Participants}

The Missouri Division of Youth Services (MDYS) houses all youth committed by the 45 courts in the Missouri juvenile justice system. With a few exceptions detailed below, this study surveyed nearly the entire population of youth currently residing in MDYS detention facilities at the time of data collection (a 3-month period in 2004). Every youth in the 32 residential facilities comprising the MDYS residential treatment system was given the opportunity to participate in this study, which included youth in minimum-, medium-, and maximum-security facilities. Maximum-security facilities housed youth with histories of crimes against persons and other serious offenses, whereas minimum- and medium-security facilities largely served youth who have committed property and other lesser offenses.

Youth in MDYS closely resembled delinquent youth in state-mandated care across the nation with regard to age, gender, severity of offenses, and percentage in care (Snyder \& Sickmund, 2006); however, Latinos were underrepresented in the MDYS sample as compared to national rates. Overall, similarities of characteristics between the MDYS sample and national samples enhance confidence that study findings may be generalized to other samples in state-mandated care facilities. The spectrum of offenses committed by youth in MDYS care were almost equally divided between felonious offenses and relatively minor offenses (e.g., "status" offenses, including truancy and running away from home that were considered offenses because of a youth's status as a juvenile; court order violations; or misdemeanors; Missouri Department of Social Services, 2004).

At the time of data collection, 740 youth were in MDYS residential care, 12 of whom were on furlough or transitioning between facilities, leaving 728 potential participants. Among these 728 youth, one youth began the interview and then chose not to complete the interview, and four youths displayed psychotic symptoms and were excluded from the sample. Thus, the final sample comprised 723 completed youth interviews (97.7\% of current MDYS residents). The study protocol was approved by the MDYS Institutional Review Board, the host university's Human Studies Committee Institutional Review Board, federal Office of Human Research Protection, and was granted a Certificate of Confidentiality by the National Institute on Drug
Abuse. Because MDYS was the legal guardian for all youth, MDYS provided informed consent for youth participation in the study.

\section{Procedure}

Data for this study was originally collected with a focus on inhalant use among incarcerated youth; however, the data collected included multiple assessments of aggressive and antisocial behaviors, specifically a measure of strong-arm bullying. Thus, this study involves secondary data analysis of original data collected. During original data collection, face-toface interviews were conducted using the Volatile Solvent Screening Inventory (VSSI) with youth who volunteered to participate in the study (Howard, Balster, Cottler, Wu, \& Vaughn, 2008). The VSSI is an extensive assessment of a respondent's use of volatile solvents as well as all other measures (described in detail below), including demographic characteristics, medical history, lifetime and annual use of substances and substance-related problems, current psychiatric symptoms, suicidality, trauma history, antisocial traits, and criminal activity. A description and copy of the VSSI is available in Howard et al. (2008). Measures are described briefly in the following section.

Before each interview commenced, interviewers ensured that they and the respondents were confident the setting afforded sufficient privacy so that their responses could not be overheard. The interviewer fully described the study to each potential respondent. This description included assurances that the youths could choose not to participate or could choose to withdraw their participation at any time without any consequence for their current stay in residential treatment. In addition, the interviewer gave each youth a brochure developed by the host university describing the participant's privacy rights and providing participants with phone numbers they could call if they had concerns or questions. MDYS also agreed to allow study participants to make these phone calls if they desired. Youth were provided with copies of their signed assent forms, which also included contact information.

After providing informed assent, trained interviewers conducted the youth interviews. All interviewers were second-year master's of social work degree students with at least one year of professional experience working in direct practice settings. Interviewer training involved an intensive full-day didactic presentation of all study measures and dyadic practice completing the measures. The interviewers' training also included a full explanation of the human subjects consent process, and all interviewers completed confidentiality pledges. An interview editor was available on-site to minimize interviewer errors. Because all MDYS residents required continuous supervision, private areas were assigned within a large 
room where three to six interviews were conducted simultaneously. Interviews took approximately 45 minutes to complete, and youth received $\$ 10.00$ for their participation. These incentive payments were deposited into the participants' individual canteen accounts at the facility for purchasing food and other items.

\section{Measurement}

\section{Correlates: Explanatory Variables}

Demographic factors. For each participant, age, sex, whether their family ever received public assistance (yes $=1$, no $=0$ ), and geographic area of family residence (urban/suburban $=1$, small town/rural $=0$ ) were recorded. The variable for participants' self-reported racial status was dichotomized (White $=1$, non-White $=0$ ) given the distribution of race in the sample: White $(55 \%)$, African American (33\%), Latino (4\%), biracial (6\%), and other $(2 \%)$.

Substance use. To assess lifetime substance use problems, the Alcohol/Drug Use Scale of the Massachusetts Adolescents Screening Instrument-2nd Version (MAYSI-2; Grisso \& Barnum, 2000) was administered to youth. This eight-item scale using yes $/$ no responses (yes $=1$, no $=0$ ) was developed to query youth involved in the juvenile justice system regarding substance-related experiences. Three scale items ask about substance use characteristics (e.g., had ever been drunk or high at school, used alcohol and drugs at the same time), and five items ask about negative consequences of substance use (e.g., been so drunk or high they could not remember what happened, done anything they wished they had not while drunk or high). Affirmative answers were summed for a total score ranging from 0 to 8 points. The MAYSI-2 has demonstrated internal consistency $(\alpha=.86)$ in previous samples (Grisso \& Barnum, 2000) and the $\alpha$ coefficient for this study was .83. In addition to substance-related problems, lifetime alcohol and tobacco use was assessed by asking participants whether they had ever used alcohol (i.e., beer, wine, liquor) or ever used tobacco (cigarettes); responses were coded as 1 for yes and 0 for $n o$.

Psychiatric variables. To assess psychiatric symptoms, all participants completed the Brief Symptom Inventory (BSI). The BSI is a 53-item instrument that uses a 5-point scale to assess the extent to which youth have been bothered $(0=$ not at all; $1=a$ little bit; 2 = moderately; $3=$ quite a bit; 4 = extremely) by specific thoughts or feelings in the past week (Derogatis, 1993). Thoughts and feelings included responses such as feeling easily annoyed or irritated, trouble remembering things, poor appetite, or temper outbursts. Items were summed to create a Global Severity Index of overall current psychiatric and emotional distress (possible range $=0$ to 212 points; $\alpha$
$=.96$ in current study). In addition, youth were asked, "Has a doctor or psychiatrist ever diagnosed you with a mental illness?" This history of mental illness diagnosis was coded dichotomously (yes $=1$, no $=0$ ).

The Psychopathic Personality Inventory Short Version (PPI-SV; Lilienfeld \& Andrews, 1996) is a 56item survey that asks youth to use a 4-point scale to rate the extent to which they feel different personality characteristics apply to them $(1=$ false, $2=$ mostly false, $3=$ mostly true, $4=$ true $)$. The current study used the Machiavellian Egocentricity subscale of the PPI-SV in the analyses. This subscale measures self-centered interactions and manipulation of others. Cronbach's alpha for the PPI-SV has been shown to be adequate in previous analyses of this sample $(\alpha=.76$; Vaughn, Howard, \& DeLisi, 2008).

Victimization. A four-item Traumatic Experiences scale adapted from the MAYSI-2 was used to assess participants' past trauma or victimization experiences (Grisso \& Barnum, 2000). Youth reported whether (yes $=1$, no $=0$ ) they had ever seen someone severely injured or killed (in person, not in the movies or on television), had a lot of bad thoughts or dreams about a bad or scary event that happened to them, had ever been badly hurt or in danger of being badly hurt or killed, and had ever experienced something very bad or terrifying. To maintain consistent measurement with the same items across male and female participants, our analysis excluded the fifth item in the MAYSI-2 scale because it was a gender-specific item. Scores were summed and ranged from 0 to 4 points, with higher scores indicating greater trauma experiences. Previous investigation found the MAYSI-2 trauma subscale to have adequate internal consistency ( $\alpha=.51-.73$; Grisso, Barnum, Fletcher, Cauffman, \& Peuschold, 2001); the revised four-item scale used in this study had a Cronbach's alpha of 69 .

Delinquency. Delinquent behavior was assessed using the Self-Report of Delinquency (SRD) developed by Elliott, Huizinga, and Menard (1989). The $S R D$ is a retrospective measure that asks youth to recall the number of times they engaged in 17 different crimes ( 7 nonviolent and 10 violent) in the year prior to incarceration. Response categories ranged from 0 (never) to 8 (two to three times per day). One item from the $S R D$ assessed strong-arm bullying other students; this item was not included in calculating youths' total delinquency. Total delinquency scores (excluding the bullying item) had a possible range of 0 to 128 points $(\alpha=.84)$.

\section{Dependent Variable}

Strong-Arm Bullying. This study used one item from the $S R D$ as a dependent ordinal measure of strong-arm bullying. This item asked youth how many times in the year prior to incarceration they had "strong-armed students (e.g., bullied, threatened them 


\section{PSYCHOLOGICAL CORRELATES OF BULLYING}

with force)." Responses for this item used the same 9point scale as other $S R D$ items (described above). This bullying item was also dichotomized to indicate whether youth had strong-arm bullied other students in the year prior to incarceration (yes $=1, n o=0)$.

\section{Data Analysis}

Less than $1 \%$ of the total data points were missing, which were imputed using the aregImpute function in the Hmisc package for R (Alzola \& Harrell, 2006). Chi-square tests and independent $t$-tests were used to compare differences between the bully and nonbully groups regarding demographic, psychosocial, and personality variables. Cramer's V was used as an effect size measure for associations based on chi-square tests and point-biserial correlations noted for bivariate relationships between dichotomous and continuous measures. Factors included in the analyses were based on previous research identifying psychosocial correlates of bullying among general population samples.

Logistic regression and ordinal logistic regression models were used to identify factors associated with ever having strong-arm bullied (a dichotomous measure) and frequency of strong-arm bullying (ordinal) during the year prior to incarceration. Thus, in the standard logistic regression model the dichotomous bullying variable (i.e., ever bullied) was regressed on psychosocial factors whereas the ordinal bullying variable (frequency of bullying during year prior to incarceration) was regressed on psychosocial factors. In addition, standard logistic regression was used to determine whether strong-arm bullying was associated with other antisocial behaviors while controlling for psychosocial factors. To determine the specific delinquent behaviors associated with participants' having bullied (i.e., before incarceration), antisocial behaviors were examined based on this population's incarceration status. Odds ratios were significant if the ratios did not bound the value of 1.0 .

\section{Results}

\section{Sample Characteristics}

For the study sample $(N=723)$ of incarcerated youth, participants' mean age was 15.5 years. The majority of the sample $(87 \%)$ was male. Participants self-reported their racial/ethnic affiliation, with slightly more than half self-identifying as White $(56 \%)$ and $44 \%$ indicating a racial/ethnic category other than White. The geographic background of the sample was almost evenly divided between youth from an urban or suburban location (53\%) and those from a rural or small town setting (47\%). The socioeconomic status of the youth's household was determined by receipt of public assistance: $41 \%$ of the sample reported having received some type of public assistance. The majority of the sample reported tobacco and alcohol use: $85 \%$ had smoked cigarettes, and $85 \%$ had used alcohol in their lifetime. Approximately $52 \%$ of the study sample self-reported committing at least one act of strong-arm bullying against another student in the year before incarceration. On a 9-point ordinal measure of bullying, the sample mean was 2.15, which corresponded to strong-arm bullying once every 2 to 3 months, and the median was 1 , which corresponded to strong-arm bullying once or twice in the past 12 months. Approximately $25 \%$ of youth who reported any strong-arm bullying in the past year indicated they participated in physically coercive behavior once a week or more.

\section{Bivariate Differences Between Bullies and Nonbullies}

Chi-square and $t$-test analyses indicated that strong-arm bullies and nonbullies did not differ significantly in regards to gender, ethnicity, urbanicity, or receipt of public assistance (see Table 1). However, youth who strong-arm bullied were significantly younger $(\mathrm{t}[719.8]=2.48, p=.013)$ than nonbullies, and strong-arm bullies had significantly higher rates of delinquency than nonbullies $(\mathrm{t}[705.1]=-11.00, p<$ .001). In addition, strong-arm bullies had significantly higher scores than nonbullies on the Machiavellian Egocentricity subscale $(\mathrm{t}[675.4]=-6.02, p<.001)$. Moreover, notable differences were observed across other psychiatric variables, with strong-arm bullies exhibiting greater impairments than nonbullies on the MAYSI-2 measures of substance use problems $(\mathrm{t}[715]=$ $-6.35, p<.001)$ and trauma exposure $(\mathrm{t}[708.4]=-3.03$, $p<.01$ ), and greater levels of distress related to psychiatric symptoms as indicated on the Global Severity Index $(\mathrm{t}[718.6]=-3.79, p<.001)$. As compared with nonbullies, strong-arm bullies reported significantly higher incidence of cigarette use $\left(\chi^{2}[1]=\right.$ 4.32, $p=.038)$ and alcohol use $\left(\chi^{2}[1]=28.39, p<\right.$ $.001)$.

\section{Logistic Regression Analysis Distinguishing Strong- Arm Bullies from Nonbullies}

Analyses using multivariate regression revealed numerous clinical and psychosocial factors that distinguished self-reported strong-armed bullies from those who did not report such behavior (see Table 2). The overall regression model exhibited a good fit with the data $\left(\operatorname{LR} \chi^{2}[13]=163.6, p<.0001\right.$, pseudo $\mathrm{R}^{2}=$ $.27)$. Older youth $(\mathrm{AOR}=.80,95 \% \mathrm{CI}=.69-.93)$ and youth from small or rural towns $(\mathrm{AOR}=.58,95 \% \mathrm{CI}$ $=40-84$ ) were less likely to have strong-arm bullied their peers. Several other risk factors were associated with having strong-arm bullied. Youth involved in 
BENDER, PERRON, HOWARD, and JENSON

Table 1

Demographic and Clinical Characteristics of 723 Incarcerated Youth With and Without a Self-Reported History of Strong-Arm Bullying

\begin{tabular}{|c|c|c|c|}
\hline Variables & $\begin{array}{c}\text { Nonbullies } \\
n=345\end{array}$ & $\begin{array}{l}\text { Bullies } \\
n=377\end{array}$ & Statistical test \\
\hline \multicolumn{4}{|l|}{ Gender: \% $(n)$} \\
\hline Male & $88.1(304)$ & $85.9(324)$ & $\chi^{2}[1]=.75, p=.386$ \\
\hline Female & $11.9(41)$ & $14.1(53)$ & Cramer's V $=.03$ \\
\hline \multicolumn{4}{|l|}{ Ethnicity: $\%(n)$} \\
\hline Non-White & $43.8(151)$ & $45.1(170)$ & $\chi^{2}[1]=.13, p=.720$ \\
\hline White & $56.2(194)$ & $54.9(207)$ & Cramer's V =.01 \\
\hline Age: Mean $(S D)_{11-20}$ & $15.6(1.2)$ & $15.4(1.3)$ & $\begin{array}{l}\mathrm{t}[719.8]=2.48, p=.013 \\
r_{\mathrm{rb}}=.09\end{array}$ \\
\hline \multicolumn{4}{|l|}{ Urbanicity: \% $(n)$} \\
\hline Rural/Small town & $44.3(153)$ & $49.6(187)$ & $\chi^{2}[1]=2.00, p=.158$ \\
\hline Urban/Suburban & $55.7(192)$ & $50.4(190)$ & Cramer's V $=.05$ \\
\hline \multicolumn{4}{|l|}{ Public Assistance: $\%(n)$} \\
\hline $\begin{array}{l}\text { No } \\
\text { Yes }\end{array}$ & $\begin{array}{l}62.9(217) \\
37.1(128)\end{array}$ & $\begin{array}{l}56.5(213) \\
43.5(164)\end{array}$ & $\begin{array}{l}\chi[1]=2.59, p=.108 \\
\text { Cramer's V =.06 }\end{array}$ \\
\hline Total delinquency: Mean $(S D)_{0-107}$ & $18.5(15.2)$ & $32.61(19.2)$ & $\begin{array}{l}\mathrm{t}[705.1]=-11.00, p<.001 \\
r_{\mathrm{pb}}=-.38\end{array}$ \\
\hline Machiavellian Egocentricity Mean $(S D)_{7-28}$ & $16.2(4.7)$ & $18.2(4.0)$ & $\begin{array}{l}\mathrm{t}[675.4]=-6.02, p<.001 \\
r_{\mathrm{pb}}=-.22\end{array}$ \\
\hline Global Severity Index: Mean $(S D)$ & $38.7(33.7)$ & $48.5(35.3)$ & $\begin{array}{l}\mathrm{t}[718.6]=-3.79, p<.001 \\
r_{\mathrm{pb}}=-.14\end{array}$ \\
\hline \multicolumn{4}{|l|}{ Previous Psychiatric Diagnosis \% ( $n$ ) } \\
\hline No & $51.3(177)$ & $45.6(172)$ & $\chi^{2}[1]=2.33, p=.127$ \\
\hline Yes & $48.7(168)$ & $54.4(205$ & Cramer's V $=.06$ \\
\hline MAYSI-2 Trauma: Mean $(S D)_{0-4}$ & $2.3(1.4)$ & $2.56(1.4)$ & $\begin{array}{l}\mathrm{t}[708.4]=-3.03, p<.01 \\
r_{\mathrm{pb}}=-.11\end{array}$ \\
\hline \multicolumn{4}{|l|}{ MAYSI-2 Substance use problems: Mean (SD) } \\
\hline $0-8$ & $3.3(2.4)$ & $4.4(2.4)$ & $\begin{array}{l}\mathrm{t}[715]=-6.35, p<.001 \\
r_{\mathrm{pb}}=-.23\end{array}$ \\
\hline \multicolumn{4}{|l|}{ Lifetime history of cigarette use: $\%(n)$} \\
\hline No & $17.4(60)$ & $11.9(45)$ & $\chi^{2}[1]=4.32, p=.038$ \\
\hline Yes & $82.6(285)$ & $88.1(332)$ & Cramer's V $=.08$ \\
\hline \multicolumn{4}{|l|}{ Lifetime history of alcohol use: $\%(n)$} \\
\hline No & $22.6(78)$ & $8.5(32)$ & $\chi^{2}[1]=28.39, p<.001$ \\
\hline Yes & $77.4(267)$ & $91.5(345)$ & Cramer's V = .20 \\
\hline
\end{tabular}

Note. All percentages are reported as column percentages unless otherwise noted; subscripts in left column indicate range of scores.

higher levels of overall delinquency $(\mathrm{AOR}=3.60,95 \%$ $\mathrm{CI}=2.58-5.04)$, and those with Machiavellian Egocentric personality characteristics $(\mathrm{AOR}=1.36$, $95 \% \mathrm{CI}=1.07-1.74)$ were more likely to report having strong-arm bullied. In addition, youth with substance use problems were significantly more likely to report using physically coercive bullying tactics in the past year $(\mathrm{AOR}=1.42,95 \% \mathrm{CI}=1.01-2.01)$. Moreover, youth who had used alcohol were twice as likely to report having strong-arm bullied as those who had not used alcohol $(\mathrm{AOR}=2.12,95 \% \mathrm{CI}=1.23-3.66)$.
Ordinal Regression Analysis of Factors Associated with Strong-Arm Bullying Frequency Before Incarceration

To identify factors associated with more frequent strong-arm bullying, an ordinal logistic regression model was used to regress youths' bullying frequencies in the year prior to incarceration on clinical and psychosocial factors (see Table 2). The overall regression model exhibited a good fit with the data (LR $\chi^{2}[13]=257.3, p<.0001$, pseudo $\mathrm{R}^{2}=.31$ ). Factors associated with more frequent strong-arm bullying were similar to the factors associated with having ever strong-arm bullied, including being younger, being from an urban or suburban area, reporting higher levels 


\section{PSYCHOLOGICAL CORRELATES OF BULLYING}

of overall delinquency $(\mathrm{AOR}=4.60,95 \% \mathrm{CI}=3.51$ 6.03), and having Machiavellian egocentric personality characteristics $(\mathrm{AOR}=1.39,95 \% \mathrm{CI}=1.12-1.73)$. In contrast to previous analyses, substance use problems were not associated with more frequent strong-arm bullying $(\mathrm{AOR}=1.24,95 \% \mathrm{CI}=.92-1.68)$, although youth who used alcohol did report more frequent strong-arm bullying $(\mathrm{AOR}=2.03,95 \% \mathrm{CI}=1.21$ 3.41).

Table 2

Multivariate Regression Analyses of Factors Associated with Dichotomous Strong-Arm Bullying Status (Yes/No) and Level (Ordinal) of Strong-Arm Bullying in Year Prior to Incarceration

\begin{tabular}{|c|c|c|c|c|}
\hline \multirow[b]{2}{*}{ Variable } & \multicolumn{2}{|c|}{ Dichotomous } & \multicolumn{2}{|c|}{ Ordinal } \\
\hline & AOR & $95 \% \mathrm{CI}$ & AOR & $95 \% \mathrm{CI}$ \\
\hline $\begin{array}{l}\text { Gender: } \\
\text { Male } \\
\text { Female }\end{array}$ & $\begin{array}{c}1.00 \\
.78\end{array}$ & $.48-1.29$ & $\begin{array}{c}1.00 \\
.83\end{array}$ & $\begin{array}{c}-- \\
.73-.94\end{array}$ \\
\hline $\begin{array}{l}\text { Ethnicity: } \\
\text { Non-White } \\
\text { White }\end{array}$ & $\begin{array}{c}.97 \\
1.00\end{array}$ & $\begin{array}{c}.65-1.45 \\
--\end{array}$ & $\begin{array}{c}.89 \\
1.00\end{array}$ & $\begin{array}{c}.64-1.24 \\
--\end{array}$ \\
\hline Age & $.80 *$ & $.69-.93$ & $.83 *$ & $.73-.94$ \\
\hline $\begin{array}{l}\text { Urbanicity: } \\
\text { Rural/Small town } \\
\text { Urban/Suburban }\end{array}$ & $\begin{array}{c}.58 * \\
1.00^{*}\end{array}$ & $\begin{array}{c}.40-.84 \\
--\end{array}$ & $\begin{array}{c}.59 * \\
1.00 *\end{array}$ & $\begin{array}{c}.43-.81 \\
--\end{array}$ \\
\hline $\begin{array}{l}\text { Public Assistance: } \\
\text { No } \\
\text { Yes }\end{array}$ & $\begin{array}{l}1.00 \\
1.36\end{array}$ & $.96-1.92$ & $\begin{array}{l}1.00 \\
1.10\end{array}$ & $.82-1.47$ \\
\hline \multicolumn{5}{|l|}{ Total delinquency } \\
\hline Machiavellian ego & $1.36^{*}$ & $1.07-1.74$ & $1.39 *$ & $1.12-1.73$ \\
\hline Global Severity Index & .87 & $.68-1.12$ & .96 & $.77-1.19$ \\
\hline Previous Psychiatric Diagnosis & 1.06 & $.74-1.52$ & 1.16 & $.86-1.58$ \\
\hline MAYSI-2 Trauma & .92 & $.61-1.40$ & .71 & $.49-1.02$ \\
\hline MAYSI-2 Substance use problems & $1.42 *$ & $1.00-2.01$ & 1.24 & $.92-1.68$ \\
\hline Lifetime history of cigarette use & .74 & $.44-1.25$ & .84 & $.54-1.33$ \\
\hline Lifetime history of alcohol use & $2.12 *$ & $1.23-3.66$ & $2.03 *$ & $1.21-3.41$ \\
\hline Model fit & \multicolumn{2}{|c|}{$\operatorname{LR} \chi^{2}[13]=163.6, p<.0001$} & \multicolumn{2}{|c|}{$\operatorname{LR} \chi^{2}[13]=257.3, p<.0001$} \\
\hline
\end{tabular}

Note. $\mathrm{AOR}=$ adjusted odds ratio. $\mathrm{CI}=$ Confidence Interval. Nonbullies were the reference group in dichotomous analyses. * denotes values that are statistically significant based on a 95\% CI that does not bound 1.0.

\section{Associations Between Antisocial Behaviors and Strong-Arm Bullying}

Logistic regression models were used to determine the associations between having ever strong-armed peers and committing other antisocial behaviors. The data for antisocial behavior (yes $=1$, no $=0$ ) for each model were regressed on whether the youth reported having ever strong-arm bullied peers (yes $=1$, no $=0$ ) and psychosocial control variables (i.e., age, sex, ethnicity, ever received public assistance, geographic area of residence, MAYSI-2 lifetime substance problems, MAYSI-2 traumatic experiences, alcohol and tobacco use, previous psychiatric diagnosis, Machiavellian Egocentrism personality, and Global Severity Index of psychiatric distress).

Table 3 shows that numerous antisocial behaviors were associated with strong-arm bullying. Most noteworthy, when compared with youth who did not bully other students, youth who reported strong-arm bullying other students were at least 4 times more likely to also report having used physically coercive 
bullying toward their parents $(\mathrm{AOR}=4.24,95 \% \mathrm{CI}=$ 2.48-7.26) and 7 times more likely to report physically coercive bullying toward teachers $(\mathrm{AOR}=7.04,95 \%$ $\mathrm{CI}=3.83-12.95)$.

Strong-arm bullies were more likely to commit several nonviolent crimes, including stealing items of varying worth (i.e., less than $\$ 5$, between $\$ 5$ and $\$ 50$, and more than $\$ 50)$, buying or selling stolen goods $(\mathrm{AOR}=1.81,95 \% \mathrm{CI}=1.27-2.58)$, and stealing drugs (AOR $=1.82,95 \% \mathrm{CI}=1.26-2.63)$. In addition, youth who reported strong-arm bullying were more than 2 times as likely to report carrying a hidden weapon
$(\mathrm{AOR}=2.23,95 \% \mathrm{CI}=1.51-3.29)$ and more than 3 times as likely to report having been in a gang fight $(\mathrm{AOR}=3.55,95 \% \mathrm{CI}=2.39-5.28)$ than nonbully peers. Violent antisocial behaviors were also more common among youth who reported having strong-arm bullied, with these bullies significantly more likely to report having attacked a person $(\mathrm{AOR}=2.67,95 \% \mathrm{CI}$ $=1.89-3.77)$. Although strong-arm bullying was not significantly associated with hitting parents or teachers, youth who reported bullying were more than 4 times as likely to report having hit other students $(\mathrm{AOR}=4.23$, $95 \% \mathrm{CI}=2.67-6.71)$.

Table 3

Logistic Regression Analyses of Antisocial Behaviors Associated with Strong-Arm Bullying Status

\begin{tabular}{lcc}
\hline Variable & AOR & $95 \%$ CI \\
\hline Stolen a motor vehicle & 1.08 & $.77-1.51$ \\
Stolen things worth more than \$50 & $1.64^{*}$ & $1.14-2.35$ \\
Bought or sold stolen goods & $1.81^{*}$ & $1.27-2.58$ \\
Stolen things worth less than \$5 & $1.76^{*}$ & $1.26-2.46$ \\
Stolen marijuana or other drugs & $1.82^{*}$ & $1.26-2.63$ \\
Avoided paying for things & $1.76^{*}$ & $1.25-2.47$ \\
Stolen things worth \$5-\$50 & $1.77^{*}$ & $1.23-2.55$ \\
Carried a hidden weapon & $2.23^{*}$ & $1.51-3.29$ \\
Been in a gang fight & $3.55^{*}$ & $2.39-5.28$ \\
Hit a teacher & 1.48 & $.94-2.32$ \\
Hit a parent & 1.26 & $.84-1.89$ \\
Hit other students & $4.23^{*}$ & $2.67-6.71$ \\
Strong-armed parents (e.g., bullied, threaten with & $4.24^{*}$ & $2.48-7.26$ \\
force) & & $3.83-12.95$ \\
Strong-armed teachers (e.g., bullied, threaten with & $7.04^{*}$ & \\
force) & & $.39-1.43$ \\
Forced someone to have sex & .75 & $1.89-3.77$ \\
Attacked someone & $2.67^{*}$ & \\
\hline
\end{tabular}

Note. $\mathrm{AOR}=$ adjusted odds ratio or odds that youth who bully would be likely to commit each behavior. $\mathrm{CI}=$ Confidence Interval. Nonbullies were the reference group in all analyses. $*$ denotes values that are statistically significant based on a 95\% CI that does not bound 1.0.

\section{Discussion}

More than half of the youth $(52 \%)$ in this sample of incarcerated juvenile offenders reported strong-arm bullying other students in the year preceding their incarceration. This rate is 3 to 4 times greater than rates of bullying in samples of the general U.S. population as reported by Glew et al. $(2008 ; 11 \%)$ and Nansel et al. (2001; 20\%). The prevalence rates for bullying found in the current study are also at the high end of the range of bullying rates reported in samples of incarcerated youth in other countries (Ireland, 2000). However, the rates we report here may underestimate overall bullying in this population because the item used to assess bullying asked only about bullying other students and specified that bullying was acts of strong- arming or threatening with force. Therefore, this narrow definition of bullying not only excluded bullying that occurred outside of school through community interactions with peers and gang-related interactions but also excluded bullying through relational or psychological means. Thus, overall bullying rates for this sample are likely to be higher than those reported here, and findings should be interpreted in light of the narrow definition used in this study.

An array of individual, social, and family characteristics was associated with strong-arm bullying others. Incarcerated youth who strong-armed their peers were younger than nonbullies. It may be that youth who enter the justice system at a younger age display a greater tendency toward aggressive behavior, 


\section{PSYCHOLOGICAL CORRELATES OF BULLYING}

which is manifested in bullying others early in life. Boys and girls were equally likely to have strong-arm bullied their peers; This finding contradicts results from previous studies indicating that male offenders are more likely than female offenders to physically bully others (Ireland, 1999; Nansel et al., 2001). However, interpretation of this finding should take into account the current study's sample of incarcerated youth and narrow definition of physically coercive bullying. Although study findings indicate incarcerated boys and girls report similar levels of physical bullying, an assessment of relational or psychological bullying might yield different results and should be investigated in future studies.

Research with general youth samples has indicated that bullying behavior is often significantly related to psychiatric problems (Kumpulainen et al., 2001). However, the relationship between psychiatric symptoms and strong-arm bullying was quite weak in our sample of incarcerated youth. As reflected in the Global Severity Index, youth who bullied others were more psychologically disturbed than nonbullies in uncontrolled analyses but those associations were not significant in controlled analyses. Similarly, uncontrolled analyses revealed more trauma experiences (as indicated by the MAYSI-2) among youth who strong-armed others, but this relationship did not remain significant after controlling for demographic, personality, and substance use variables. It is possible that the stronger association between substance use and bullying overshadowed mental health and trauma relationships in the multivariate analysis. Thus, although mental health is related to bullying, it appears that psychological status is not as strongly related as active detrimental behaviors such as substance use. Further, stigma and social desirability bias may have led youth to under report their mental health symptoms and, thus, yielded an underestimate of the relationship between mental health and strong-arm bullying. Further work is needed to study the influence of specific mental health problems on bullying among incarcerated youth in the United States. Investigation of possible relationships between bullying behavior and oppositional defiant disorder and conduct disorder in this population is warranted. Interestingly, psychopathic personality characteristics, specifically Machiavellian egocentrism (characterized by selfcentered and manipulative tendencies), increased the odds for strong-arm bullying and was associated with more frequent bullying. Thus, although mental health symptoms showed mixed results, the egocentrism personality trait appeared to be a more salient factor among youth offenders who bully.

Incarcerated bullies were more likely than nonbullies to engage in other high-risk behaviors, which is consistent with investigations of bullying using school-based samples (Berthold \& Hoover, 2000; Nansel et al., 2001). Substance-related problems, including use of alcohol and cigarettes, were associated with physically coercive bullying, although only alcohol use increased the frequency of this behavior. In addition to using substances, bullies reported high levels of violent and nonviolent coercive behaviors. Not only did strong-arm bullies intimidate other students, but they were also much more likely than other youth to bully their parents and teachers. These findings may reflect a general trend of aggression among incarcerated youth who engage in physically coercive bullying behaviors. Thus, intervening to reduce high-risk youths' bullying behavior-if effective - is likely to have a positive effect on youths' relationships at school and at home; this possibility advocates for the importance of addressing generalized aggression.

Strong-arm bullying was associated with physical violence and involvement in gang-related violence. This relationship is to be anticipated, considering this study's narrow definition of bullying as a physical behavior. Viljoen and colleagues (2005) reported a similar association between bullying and gang affiliation in a study involving incarcerated youth. In their study, bullies were 2 times more likely than nonbullies to be a member of a juvenile gang. It may well be that the intimidation and domination of others through threats or violence that is characteristic of bullying is also common among gang-involved youth. Indeed, evidence of the ability to physically threaten and bully others may even be a necessary condition or prerequisite to joining a gang. Overall, these findings are important because they suggest that early involvement in physically threatening behavior (i.e., bullying) may escalate to more serious aggressive behavior and offending patterns that increase the risk for juvenile justice involvement as young people grow older.

In sum, incarcerated youth who strong-arm bully their peers may represent a subsample of juvenile offenders who display a greater propensity to engage in aggression and violence. The modal bully in this sample was likely to be living in an urban setting in which she or he participated in frequent forms of antisocial and delinquent behavior. Bullying among incarcerated youth was also associated with greater Machiavellian egocentricity, higher alcohol use and more alcohol-related problems.

\section{Limitations}

Certain limitations should be considered when interpreting the findings of this study. The study used a cross-sectional design; thus, although significant associations are presented, causal ordering cannot be determined. In addition, because bullying was not the 
primary focus of the original study and data collection efforts, only a single-item measure of strong-arm bullying was available for this analysis. Although previous work on bullying has used individual criterion to examine relationships with other criteria (e.g., Vaughn et al., in press), future studies of bullying behavior among youth incarcerated in the United States should use established multi-item bullying measures to increase reliability. Further, although our sample represented a comprehensive statewide population of incarcerated youth, comparisons between and among state populations should be made cautiously. It should be noted that our analyses did not control for factors related to juvenile justice sentencing such as length of sentence, length of stay, and offense type. Future research should investigate whether such variables may account for further unobserved heterogeneity. Finally, the data were obtained from youth self-reports, which raises questions of social desirability bias and validity, although all efforts were made to assure confidentiality and elicit valid information.

\section{Implications for Policy and Practice}

Our findings suggest that many adolescents who become involved with the juvenile justice system have engaged in physically threatening bullying prior to incarceration. This pattern of antisocial conduct suggests that, for some youth, bullying may be a precursor for involvement in more serious forms of aggression. Thus, preventing bullying during childhood may be a critical step in avoiding the types of aggressive and violent conduct that may lead to incarceration.

Prevention efforts aimed at bullying include varying approaches such as schoolwide programs (Olweus, 1994, 2004), classroom management (Roland \& Galloway, 2002), peer support (Cowie \& Wallace, 2000), playground aggression reduction (Cunningham et al., 1998; Frey et al., 2005), and social and emotional skills training (Jenson, Dieterich, Rinner, Washington, $\&$ Burgoyne, 2006). To date, schoolwide interventions such as the Olweus Bully Prevention Program have yielded the most positive effects in reducing bullying (Olweus, 2004). In addition, limited evidence suggests that skills-training curricula can reduce bully victimization among elementary-school age children (Jenson \& Dieterich, 2007). Findings from recent research have indicated a national reduction in physical bullying among the general population, which some have suggested may correlate with the proliferation of bullying prevention programs in schools (Finkelhor, Turner, Ormrod, \& Hamby, 2010). The current study raises questions regarding whether these prevention programs adequately intervene with the population of youth at-risk for future incarceration. Our findings point to generalized delinquency and substance abuse behaviors that are highly correlated with bullying among this high-risk sample of youth. This relationship suggests that in addition to antibullying interventions, schools should target delinquency and substance abuse prevention efforts toward youth who are deemed high risk, whether through classroom behaviors or screening tools.

Treatment programs in the justice system that seek to reduce or stop bullying behavior once it has been initiated are limited. Skills-based curricula that are focused on rehabilitating juveniles, which are common in many U.S. juvenile correctional facilities, address a range of topics including skills for refusing substances, managing anger, and enhancing communication with others. However, these programs seldom focus on bullying behavior per se. Therefore, skills training interventions designed for use in juvenile justice programs should be adapted to include greater content on bullying and victimization. A young person's ability to respond calmly and assertively to high-risk situations that involve the possibility of aggression or violence is likely an important factor in moderating or reducing risk for subsequent bullying or victimization (Espelage, Bosworth, \& Simon, 2001; Schwartz, 2000). Moreover, youth who strong-arm bully others may need to change cognitive distortions regarding the acceptability of using physical force to achieve social and material goals. Thus, it follows that strategies aimed at teaching social and emotional skills may help youth involved with the juvenile justice system to develop socially appropriate strategies for meeting their needs. Our findings also point to patterns of behavior among incarcerated youth that include substance abuse and bullying parents. This behavior pattern suggests that skills-based interventions addressing bullying may be more effective if they include training content that is related to substance use and aggression toward family members. Further, such treatment elements should help troubled youth develop emotionally regulated responses in the broader contexts of peer influence and family communication.

Finally, considering the elevated rates of strongarm bullying among this sample of incarcerated youth and the strong association between bullying and other antisocial behaviors, bullying in juvenile justice programs should be addressed using transparent and clear standardized protocols. Reducing physically coercive bullying in incarceration facilities is likely to reduce violence and increase safety for youth and staff. Juvenile justice personnel should receive training in recognizing common risks for bullying and be equipped with intervention protocols to diffuse bullying situations. Lessons might be learned from the justice system in the United Kingdom. Current public policy in the United Kingdom mandates that all correctional facilities implement antibullying strategies. The resulting Safer Custody policies aim to create a safe institutional environment in which 


\section{PSYCHOLOGICAL CORRELATES OF BULLYING}

bullying threats are deemed unacceptable, victims of bullying can anonymously report bully incidents, and everyone within the prison shares a responsibility to stop bullying via reporting incidents and intervening through sentencing plans. These programs and policies should be reviewed and considered for adoption in the U.S. juvenile justice system.

\section{Author Note}

Kimberly Bender is an assistant professor at the University of Denver, Graduate School of Social Work, kimberly.bender@du.edu

Brian Perron is an assistant professor at the University of Michigan, School of Social Work, beperron@umich.edu

Matthew O. Howard is the Frank A. Daniels, Jr. Distinguished Professor of Human Services Policy Information at the University of North Carolina Chapel Hill, School of Social Work, mohoward@email.unc.edu

Jeffrey M. Jenson is the Philip D. and Eleanor G. Winn Professor of Children and Youth at Risk, and the Associate Dean for Research at the University of Denver, Graduate School of Social Work, Jeffrey.Jenson@du.edu

\section{References}

Alzola, C., \& Harrell, F. E. (2006). An introduction to $S$ and the Hmsic design libraries. Retrieved from http://biostat.mc.vanderbilt.edu/twiki/pub/Main/R S/sintro.pdf

Berthold, K. A., \& Hoover, J. H. (2000). Correlates of bullying and victimization among intermediate students in the Midwestern USA. School Psychology International, 21, 65-78. doi:10.1177/0143034300211005

Brofenbrenner, U. (1994). Ecological models of human development. In International encyclopedia of education, Vol. 3 (2nd ed.). Oxford, UK: Elsevier Sciences.

Connell, A., \& Farrington, D. (1996). Bullying amongst incarcerated young offenders: Developing an interview schedule and some preliminary results. Journal of Adolescence, 19, 75-93. doi:10.1006/jado.1996.0007

Connolly, I., \& O’Moore, M. (2003). Personality and family relations of children who bully. Personality and Individual Differences, 35, 559-567. doi:10.1016/S0191-8869(02)00218-0

Coolidge, F. L., DenBoer, J. W., \& Segal, D. L. (2004). Personality and neuropsychological correlates of bullying behavior. Personality and Individual
Differences, 36, 1559-1569. doi:10.1016/j.paid.2003.06.005

Cowie, H., \& Wallace, P. (2000). Peer support into action. London, UK: Sage.

Cunningham, C. E., Cunningham, L. J., Martorelli, V., Tran, A., Young, J., \& Zacharias, R. (1998). The effects of primary division, student-mediated conflict resolution programs on playground aggression. Journal of Child Psychology and Psychiatry, 39, 653-662. doi:10.1017/S0021963098002558

Derogatis, L. R. (1993). BSI bibliography. Minneapolis, MN: National Computer Systems.

Eisenberg, M. E., Neumark-Sztainer, D., \& Story, M. (2003). Associations of weight-based teasing and emotional well-being among adolescents. Archives of Pediatric and Adolescent Medicine, 157, 733738. doi:10.1001/archpedi.157.8.733

Elliot, D. S., Huizinga, D., \& Menard, S. (1989). Multiple problem youth: Delinquency, substance abuse, and mental health problems. New York, NY: Springer-Verlag.

Espelage, D. L., Bosworth, K., \& Simon, T. R. (2001). Short-term stability and change of bullying in middle school students: An examination of demographic, psychosocial, and environmental correlates. Violence and Victims, 16, 411-426.

Estell, D. B., Farmer, T. W., \& Cairns, B. D. (2007). Bullies and victims in rural African American youth: Behavioral characteristics and social network placement. Aggressive Behavior, 33, 145 159. doi:10.1002/ab.20176

Finkelhor, D., Turner, H., Ormrod, R., \& Hamby, S. L. (2010). Trends in childhood violence and abuse exposure. Archives of Pediatrics and Adolescent Medicine, 164, 238-242. doi:10.1001/archpediatrics.2009.283

Frey, K. S., Hirschstein, M. K., Snell, J. L., Van Schoiack Edstrom, L., MacKenzie, E. P., \& Broderick, C. J. (2005). Reducing playground bullying and supporting beliefs: An experimental trial of the Steps to Respect program. Developmental Psychology, 41, 479-491. doi:10.1037/0012-1649.41.3.479

Glew, G. M., Fan, M., Katon, W., \& Rivara, F. P. (2008). Bullying and school safety. Journal of Pediatrics, 152, 123-128. doi:10.1016/j.jpeds.2007.05.045

Grisso, T., \& Barnum, R. (2000). Massachusetts Youth Screening Instrument-Second Version: User's manual and technical reports. Boston: University of Massachusetts Medical School.

Grisso, T., Barnum, R., Fletcher, K. E., Cauffman, E., \& Peuschold, D. (2001). Massachusetts Youth Screening Instrument for mental health needs of 
juvenile justice youths. Journal of the American Academy of Child and Adolescent Psychiatry, 40, 541-548. doi:10.1097/00004583-200105000$\underline{00013}$

Howard, M. O., Balster, R. L., Cottler, L. B., Wu, L-T, \& Vaughn, M. G. (2008). Inhalant use among incarcerated adolescents in the United States: Prevalence, characteristics, and correlates of use. Drug Alcohol Dependence, 93, 197-209. doi:10.1016/j.drugalcdep.2007.08.023

Ireland, J. L. (1999). Bullying behaviors among male and female prisoners: A study of adult and young offenders. Aggressive Behavior, 25, 161-178. doi:10.1002/(SICI)10982337(1999)25:3<161::AID-AB1>3.0.CO;2-\#

Ireland, J. L. (2000). Bullying among prisoners: A review of research. Aggression and Violent Behavior, 5, 201-215. doi:10.1016/S13591789(98)00031-7

Ireland, J. L., \& Archer, J. (2004). Association between measures of aggression and bullying among juvenile and young offenders. Aggressive Behavior, 30, 29-42. doi:10.1002/ab.20007

Ireland, K. L., \& Monaghan, R. (2006). Behaviors indicative of bullying among young and juvenile male offenders: A study of perpetrator and victim characteristics. Aggressive Behavior, 32, 172-180. doi:10.1002/ab.20116

Ireland, J .L., \& Power, C. L. (2004). Attachment, emotional loneliness, and bullying behavior: A study of adult and young offenders. Aggressive Behavior, 30, 298-312. doi:10.1002/ab.20035

Jenson, J. M., \& Dieterich, W.A. (2007). Effects of a skills-based prevention program on bullying and bully victimization among elementary school children. Prevention Science, 8, 285-296. doi:10.1007/s11121-007-0076-3

Jenson, J. M., Dieterich, W. A., Rinner, J. R., Washington, F., \& Burgoyne, K. (2006). Implementation and design issues in grouprandomized prevention trials: Lessons from the Youth Matters public schools study. Children and Schools, 28, 207-218.

Kumpulainen, K., Rasanen, E., \& Henttonen, I. (1999). Children involved in bullying: Psychological disturbance and persistence of involvement. Child Abuse \& Neglect, 23, 1253-1261. doi:10.1016/S0145-2134(99)00098-8

Kumpulainen, K., Rasanen, E., \& Puura, K. (2001). Psychiatric disorders and the use of mental health services among children involved in bullying. Aggressive Behavior, 27, 102-110. doi:10.1002/ab.3

Lilienfeld, S. O., \& Andrews, B. P. (1996). Development and preliminary validation of a selfreport measure of psychopathic personality traits in noncriminal populations. Journal of Personality Assessment, 66, 488-524. doi:10.1207/s15327752jpa6603_ 3

Missouri Department of Social Services. (2004). Division of Youth Services annual report FY2003. (National Criminal Justice Reference Service Document No. NCJ 206512). Retrieved from http://www.ncjrs.gov/App/Publications/abstract.as px?ID=206512

Nansel, T. R., Overpeck, M., Pilla, R. S., Ruan, W. J., Simons-Morton, B., \& Scheidt, P. (2001). Bullying behaviors among US youth: Prevalence and association with psychosocial adjustment. Journal of American Medical Association, 285, 2094-2100. doi:10.1001/jama.285.16.2094

Olweus, D. (1994). Bullying at school: Long-term outcomes for the victims and an effective schoolbased intervention program. In: L. R. Huesmann (Ed.), Aggressive behavior: Current perspectives. (pp. 97-130). New York, NY: Plenum Press.

Olweus, D. (1999). Sweden. In Smith, P. K., Morita, Y., Junger-Tas, J., Olweus, D., Catalano, R. \& Slee, P. (Eds.), The nature of school bullying: A cross-national perspective (pp. 7-27). New York, NY: Routledge.

Olweus, D. (2004). The Olweus Bullying Prevention Programme: Design and implementation issues and a new national initiative in Norway. In P. K. Smith, D. Pepler, \& K. Rigby (Eds.), Bullying in schools. How successful can interventions be? (pp. 13-36). Cambridge, UK: Cambridge University Press.

Olweus, D., Limber, S., \& Mihalic, S. (1999). Blueprints for violence prevention, book nine: Bullying prevention program. Boulder, CO: Center for the Study and Prevention of Violence.

Power, K. G., Dyson, G. P., \& Wozniak, E. (1997). Bullying among Scottish young offenders: Inmates' self-reported attitudes and behavior. Journal of Community and Applied Social Psychology, 7, 209-218. doi:10.1002/(SICI)10991298(199706)7:3<209::AID-CASP419>3.0.CO;2-3

Roland, E., \& Galloway, D. (2002). Classroom influences on bullying. Educational Research, 44, 299-312. doi:10.1080/0013188022000031597

Schwartz, D. (2000). Subtypes of victims and aggressors in children's peer groups. Journal of Abnormal Child Psychology, 28, 181-192. doi:10.1023/A:1005174831561

Snyder, H. N., \& Sickmund, M. (2006). Juvenile offenders and victims: 2006 national report (NCJ Number 212906). Washington, DC: U.S. Department of Justice, Office of Justice Programs, Office of Juvenile Justice and Delinquency Prevention. Retrieved from 
http://ojjdp.ncjrs.gov/ojstatbb/nr2006/downloads/ NR2006.pdf

Sourander, A., Jenson, P., Ronning, J. A., Niemela, S., Helenius, H., Sillanmaki, L.,... Almqvist, F. (2007). What is the early adulthood outcome of boys who bully or are bullied in childhood? The Finnish "From Boy to a Man" study. Pediatrics, 120, 397-404. doi:10.1542/peds.2006-2704

Vaughn, M. G., Fu, Q., Bender, K., Delisi, M., Beaver, K. M., Perron, B. E., \& Howard, M.O. (in press).

Psychiatric correlates of bullying in the United States: Findings from a national sample.

Psychiatric Quarterly. doi: 10.1007/s11126-0109128-0

Vaughn, M. G., Howard, M. O., \& DeLisi, M. (2008). Psychopathic personality traits and delinquent careers: An empirical investigation. International Journal of Law and Psychiatry, 31, 407-416. doi:10.1016/j.ijlp.2008.08.001

Viljoen, J. L., O'Neill, M. L., \& Sidhu, A. (2005). Bullying behaviors in female and male adolescent offenders: Prevalence, types, and association with psychosocial adjustment. Aggressive Behavior, 31, 521-536. doi:10.1002/ab.20036 